OPEN ACCESS

Edited by:

Jixin Zhong,

Case Western Reserve University, United States

Reviewed by: Ankit Saxena,

National Institutes of Health $(\mathrm{N} / \mathrm{H})$, United States

Krzysztof Guzik,

Jagiellonian University, Poland

${ }^{*}$ Correspondence: Jingguo Zhou jgzhou@nsmc.edu.cn; Yangang Wang wangyg1966@126.com; Qing-Sheng M qmi1@hfhs.org

tThese authors have contributed equally to this work.

Specialty section:

This article was submitted to Inflammation,

a section of the journa

Frontiers in Immunology

Received: 15 September 2017 Accepted: 20 November 2017 Published: 12 December 2017

Citation:

Wang J, Yang $Q$, Zhang $Q$, Yin C, Zhou L, Zhou J, Wang Y and Mi Q-S (2017) Invariant Natural Killer T Cells Ameliorate Monosodium Urate Crystal-Induced Gouty Inflammation in Mice.

Front. Immunol. 8:1710 doi: 10.3389/fimmu.2017.01710

\section{Invariant Natural Killer T Cells Ameliorate Monosodium Urate Crystal-Induced Gouty Inflammation in Mice}

\author{
Jie Wang ${ }^{1,2,3+}$, Qibin Yang ${ }^{2,3,4+}$, Quanbo Zhang ${ }^{2,3,5+}$, Congcong Yin ${ }^{2,3}$, Li Zhou ${ }^{2,3,6}$, \\ Jingguo Zhou ${ }^{4 *}$, Yangang Wang ${ }^{1 *}$ and Qing-Sheng $\mathrm{Mi}^{2,3,6 *}$
}

'Department of Endocrinology, Affiliated Hospital of Qingdao University, Qingdao, China, ${ }^{2}$ Immunology Research Program, Henry Ford Cancer Institute, Henry Ford Health System, Detroit, MI, United States, ${ }^{3}$ Center for Cutaneous Biology and Immunology Research, Department of Dermatology, Henry Ford Health System, Detroit, MI, United States, ${ }^{4}$ Department of Rheumatology, Affiliated Hospital of North Sichuan Medical College, Nanchong, China, ${ }^{5}$ Department of Gerontology, Affiliated Hospital of North Sichuan Medical College, Nanchong, China, ${ }^{6}$ Department of Internal Medicine, Henry Ford Health System, Detroit, MI, United States

Gout is an inflammatory arthritis caused by deposition of intra-articular monosodium urate (MSU) crystal. Previous studies have focused on resident macrophage, infiltrating monocyte, and neutrophil responses to MSU crystal; yet the mechanisms of cellular changes and the potential involvement of other regulatory immune cells remain largely unknown. Invariant natural killer T (iNKT) cells, an innate type of T cell, are involved in the development of various inflammatory diseases. Here, we investigate the role of iNKT cells in MSU crystal-induced gouty inflammation. MSU crystal-induced inflammatory profiles in an air-pouch model were examined in iNKT-deficient CD1d knockout (KO) and wild-type (WT) control mice. To explore potential mechanisms of iNKT cell regulation of gouty inflammation, we cocultured $\mathrm{CD}^{+}{ }^{+}$or $\mathrm{CD} 4^{-}{ }^{-} \mathrm{NKT}$ cells with bone marrow-derived macrophages (BMDMs). We found that iNKT cells quickly migrated to the site of inflammation upon MSU crystal stimulation in WT mice. The total number of infiltrating cells in CD1d KO mice, especially neutrophils, was dramatically increased at 6 and $12 \mathrm{~h}(P<0.01)$ post-MSU crystal challenge, compared with WT controls. BMDMs cocultured with $\mathrm{CD}^{+}{ }^{+}$NKT cells produced less tumor necrosis factor- $\alpha$ and expressed higher levels of M2 macrophage markers, including Clec7a, Pdcd1lg2, and interleukin-4 $(P<0.01)$, compared with BMDMs cocultured with CD4- ${ }^{-}$NKT cells or conventional CD4+ ${ }^{+}$cells. CD4+ ${ }^{+}$NKT cells are one of the key regulators of MSU crystal-induced gouty inflammation through the control of macrophage polarization. iNKT cells may serve as a new therapeutic target for gout.

Keywords: invariant natural killer T cells, gout, macrophage, polarization, tumor necrosis factor- $\alpha$

\section{INTRODUCTION}

Gout is a paradigm of acute, self-limited inflammation caused by the deposition of intra-articular monosodium urate (MSU) crystal (1). During the progression of the inflammatory response, MSU crystal provides both of extracellular and intracellular danger signals (2), whose recognition by toll-like receptor 2 (TLR2) and TLR4, as well as CD14, expressed on the surface of monocytes/ 
macrophages would initiate MSU crystal uptake (3-5). Monocytes stimulated by MSU crystal can polarize into hyper-inflammatory M1 macrophages, which initiate inflammation via fully functional phagocytizing MSU crystal and delivering to cytoplasmic NACHT-LRR-PYD-containing protein-3 (NALP3) inflammasome, thereby producing tumor necrosis factor- $\alpha$ (TNF- $\alpha)$ and interleukin-1 $\beta$ (IL-1 $\beta$ ), both are known as highly inflammatory cytokines, and promoting secondary neutrophil physiologic flow into the site of inflammation $(6,7)$. In contrast to M1 macrophages, anti-inflammatory M2 macrophages can dampen acute MSU crystal-induced inflammation and suppress caspase-1 activation and IL- $1 \beta$ production (8). The polarization from M1 into M2 macrophages in the development of gout may contribute to self-recovery. However, it is still unclear how this process is being regulated.

Invariant natural killer $\mathrm{T}(i \mathrm{NKT})$ cells are innate $\mathrm{T}$ cells that develop in the thymus and are selected by the MHC I homolog molecule CD1d on double-positive (DP) thymocytes (9). Based on their cytokine production profiles, $i$ NKT cells are further subdivided into NKT1, NKT2, and NKT17, while the majority of $\mathrm{CD} 4{ }^{+} i \mathrm{NKT}$ cells are NKT2 in mice, and they are activated by glycolipid antigens presented by CD1d on antigen-presenting cells (APCs) such as macrophages and dendritic cells. Upon activation, the subsets of $i \mathrm{NKT}$ cells differentially influence the immune response, producing either Th1 cytokines, such as interferon- $\gamma($ IFN- $\gamma)$ and IL-2, or Th2 cytokines, such as IL-4 and IL-10 (10). Recently, a number of studies have reported that $i$ NKT cells play a major role in mediating joint inflammation, including that of rheumatoid arthritis $(11,12)$. Nonetheless, the involvement of $i \mathrm{NKT}$ cells in gouty inflammation has yet to be clarified. In this study, we produced MSU crystalinduced gouty inflammation in a synovium-like subcutaneous air-pouch model using $i$ NKT cell-deficient mice to identify the protective role of $i \mathrm{NKT}$ cells in MSU crystal-induced gouty inflammation. Our bone marrow-derived macrophage (BMDM)- $i$ NKT coculture experiment indicates the regulatory role of $i$ NKT cells in macrophage polarization, which could contribute to the protective function of $i$ NKT cells in gouty inflammation.

\section{MATERIALS AND METHODS}

\section{Mice}

CD1d knockout $(\mathrm{KO})$ mice on a $\mathrm{C} 57 \mathrm{BL} / 6$ background and wild-type (WT) C57BL/6 mice were purchased from the Jackson Laboratory and housed in a specific pathogen-free barrier unit. Experiments were conducted at 8-12 weeks of age and gender matched. Animal handling and the experimental procedures were approved by Institutional Animal Care and Use Committee of Henry Ford Health System.

\section{Subcutaneous Air-Pouch Model}

Injection of $5 \mathrm{~mL}$ of air into the subcutaneous tissue on the back of mice was followed by injection of an additional $3 \mathrm{~mL}$ of air on day 3 and day 5. On day 7, MSU crystal ( $3 \mathrm{mg}$ in $1 \mathrm{~mL}$ ) was injected into the air-pouch cavities, and cells were harvested with $2 \mathrm{~mL}$ PBS at 3, 6, or $12 \mathrm{~h}$ for flow cytometry and enzyme-linked immunosorbent assays (ELISA) analyses (Figure 1A).

\section{Purification of $i$ NKT and $\mathrm{CD}^{+}{ }^{+}$T Cells}

Total spleen cells from WT mice were first stained with antimouse CD 8 biotin and anti-mouse B200 biotin Abs, then CD8 ${ }^{+}$ and $\mathrm{B} 220^{+}$cells were depleted with anti-biotin beads using auto MACS (Miltenyi Biotec). Negatively selected cells were then stained with anti-mouse TCR- $\beta$, anti-mouse CD4 Ab, and PBS57CD1d tetramers. $\mathrm{CD}^{+}{ }^{+} i \mathrm{NKT}$ cells, CD4 ${ }^{-} i \mathrm{NKT}$ cells, and CD4 T cells (>97\% purity) were sorted by BD FACS Aria II.
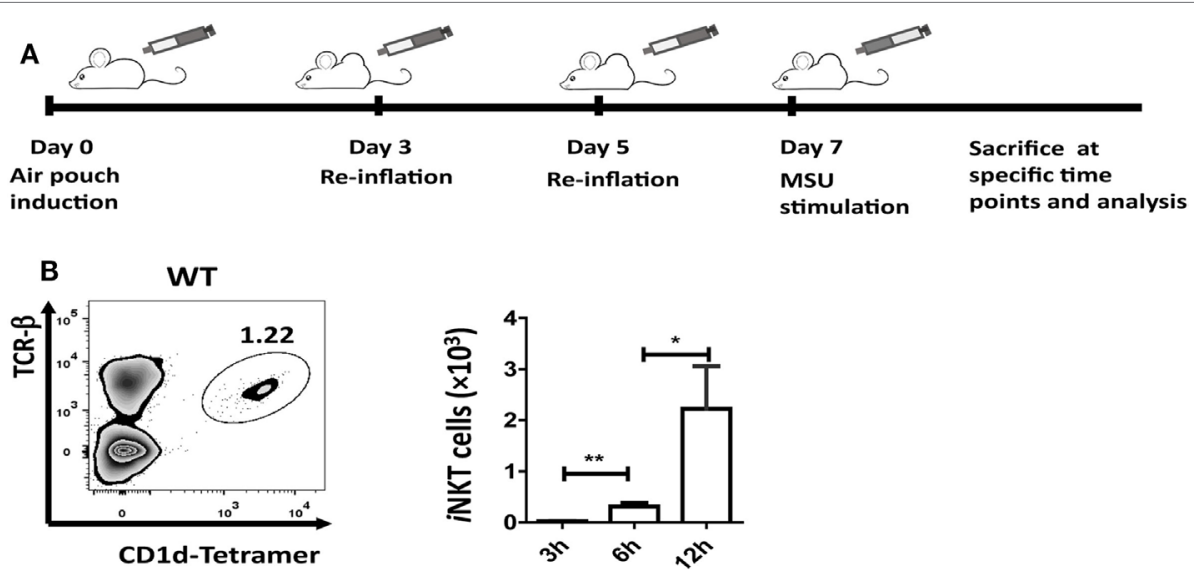

FIGURE 1 | Invariant natural killer T (iNKT) cells are recruited to the site of inflammation induced by monosodium urate (MSU) crystal. (A) Outline of the synoviumlike mouse subcutaneous air-pouch model. Subcutaneous air pouches were generated by injection of $5 \mathrm{~mL}$ air into the subcutaneous tissue of the back, followed by injection of another $3 \mathrm{~mL}$ of air at day 3 and day 5 . At day $7, \mathrm{MSU}$ crystal ( $3 \mathrm{mg}$ in $1 \mathrm{~mL}$ ) was injected into air-pouch cavities. (B) Flow cytometry analysis

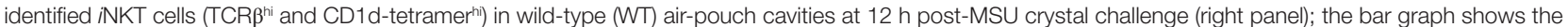
absolute number of $i$ NKT cells infiltrating the air-pouch cavities at different time points (left panel). Results are representative of three independent experiments. Values are the mean and SEM ( $n=3-4$ per group). Significance for all data was determined by unpaired Student's $t$-test: ns, not significant; ${ }^{\star} P \leq 0.05$; ${ }^{\star \star} P \leq 0.01$. 


\section{iNKT-BMDM Coculture Assay}

$\mathrm{BM}$ cells from WT or CD1d $\mathrm{KO}$ mice were incubated in culture media (RPMI with 10\% FBS and $30 \mathrm{ng} / \mathrm{mL}$ M-CSF) for 7 days to induce BMDMs (M0). BMDMs were pre-loaded with $\alpha$-galactosylceramide ( $\alpha$-GalCer, $1 \mu \mathrm{g} / \mathrm{mL}$ ) for $6 \mathrm{~h}$ before they were cocultured with sorted $\mathrm{CD} 4^{+} i \mathrm{NKT}$ cells, $\mathrm{CD} 4^{-} i \mathrm{NKT}$ cells, or $\mathrm{CD}^{+} \mathrm{T}$ cells, respectively, at a 2:1 ratio for $36 \mathrm{~h}$, followed by stimulation with MSU crystal $(50 \mu \mathrm{g} / \mathrm{mL})$ for $4 \mathrm{~h}$ with or without $i$ NKT cells. After MSU crystal stimulation, BMDMs were collected for flow cytometry analysis or qRT-PCR.

\section{Flow Cytometry}

Single-cell suspensions were washed twice with staining buffer and incubated with Fc block (clone 2.4G2). The following conjugated mAbs were used for flow cytometry analysis: TCR-beta (H57-597), PBS57-CD1d tetramers, F4/80 (BM8), Ly6G (1A8), and TNF- $\alpha$ (MP6-XT22). Dead cells were first gated out by propidium iodide (PI) staining. All mAbs were purchased from $\mathrm{BD}$ biosciences or eBioscience. Data were analyzed using FlowJo software.

\section{MSU Phagocytosis of Macrophages}

The peritoneal cells were harvested at $6 \mathrm{~h}$ after MSU crystal (3 mg in $0.5 \mathrm{~mL}$ ) treatment through peritoneal cavity. The phagocytosis of MSU crystals was determined by analyzing the side scatter (SSC) change in the flow cytometry.

\section{RNA Extraction and Quantitative RT-PCR}

Total RNA was extracted from BMDMs using a Mammalian Total RNA Miniprep Kit (Sigma). Q-PCR data collected on the QuantStudio 7 were normalized to the $\beta$-actin gene in the corresponding sample. Primer sequences are listed in Table S1 in Supplementary Material.

\section{Enzyme-Linked Immunosorbent Assays}

Cytokines in the supernatant of air-pouch cavities were measured using the ELISA Ready-Set-Go kit (eBioscience).

\section{Statistical Analysis}

Statistical analysis was performed with Prism 7.0 (GraphPad Software). The two-tailed Student's $t$-test was used. Differences were considered statistically significant when $P<0.05$.

\section{RESULTS}

\section{iNKT Cells Are Quickly Recruited into the Inflammatory Site Induced by MSU Crystal}

The air-pouch inflammation model was used for the investigation of synovial inflammation-mediated by MSU. To determine whether $i \mathrm{NKT}$ cell recruitment is a general feature in MSU crystal-induced gouty inflammation, cellular components in the washing fluid of the air-pouch cavity were analyzed by flow cytometry at different time points post-MSU crystal challenge. The $i$ NKT cell population was identified by CD1d-tetramer and anti-TCR $\beta$ staining (Figure 1B). To our surprise, $i$ NKT cells were recruited into the air-pouch cavities starting at $3 \mathrm{~h}$ and reached the peak at $12 \mathrm{~h}$ post-MSU crystal challenge (Figure 1B). Thus, it is reasonable to speculate that the $i \mathrm{NKT}$ cells recruited to sites of inflammation may have a role in the regulation of gout development.

\section{iNKT-Deficient Mice Developed More} Severe MSU Crystal-Induced Inflammation CD1d is required for $i \mathrm{NKT}$ cell selection in the thymus and CD1d $\mathrm{KO}$ mice fail to develop $i \mathrm{NKT}$ cells. As shown in Figure 2A, there is no $i$ NKT cell migration into air-pouch cavities of CD1d KO mice upon MSU crystal stimulation. To understand the function of $i$ NKT cells in MSU crystal-induced gouty inflammation, we examined inflammatory profiles in WT mice and $i$ NKT-null CD1d KO mice using an air-pouch gouty model. Upon MSU crystal stimulation, the total inflammatory cell number in the washing fluid from air-pouch cavities was significantly increased in $\mathrm{CD} 1 \mathrm{~d} \mathrm{KO}$ mice compared with WT mice at $6 \mathrm{~h}(P<0.01)$ and $12 \mathrm{~h}(P<0.01)$ post-MSU crystal challenge (Figure $2 \mathrm{~B}$ ). We next evaluated neutrophils and macrophages in the washing fluid of air-pouch cavities by flow cytometry (Figure 2C). Even though the frequencies of neutrophils were not significantly increased, the absolute number of neutrophils increased dramatically $(P<0.05$ at $6 \mathrm{~h}, P<0.01$ at $12 \mathrm{~h})$ in CD1d KO mice. Nevertheless, no significant changes in frequency or number of macrophages were observed (Figure 2D). Therefore, the mice without $i$ NKT cells developed more severe MSU crystal-induced inflammation.

Next, the levels of IL- 4 and IL- $1 \beta$ in the supernatants from air-pouch cavities were analyzed by ELISA. As expected, both cytokines were elevated at $3 \mathrm{~h}$ following MSU crystal treatment in WT mice, then quickly downregulated at 6 and $12 \mathrm{~h}$ (Figure 2E). Interestingly, the level of IL- $1 \beta$ was dramatically increased in CD1dKO mice compared with WT mice at $6 \mathrm{~h}$, whereas IL- 4 was significantly reduced in CD1dKO mice at $3 \mathrm{~h}$ post-MSU crystal challenge. Thus, $i$ NKT cells may regulate cytokine production, reducing IL-1 $\beta$ but increasing IL- 4 production by macrophages. Taken together, these results suggest that $i \mathrm{NKT}$ cell deficiency significantly enhances the inflammatory response to MSU crystal in vivo.

\section{Lack of CD1d in Macrophages Does Not Affect Their MSU Crystal Phagocytosis}

The uptake of MSU crystal by macrophages is a feature for recognition by NALP3 inflammasome, thereby triggering caspase-1 activation and IL- $1 \beta$ processing $(7,13)$. Recently, Liu-Bryan et al. found that CD14 mediated ingestion of MSU crystal was able to induce an inflammatory response, leading to IL- $1 \beta$ release, which, however, is independent of modulation of MSU crystal uptake (5, 14). To explore if the increased production of IL-1 $\beta$ in CD1d KO air-pouch cavities was due to the modulation of capacity of MSU crystal uptake in the deletion of $i \mathrm{NKT}$ cells, we next preformed macrophage MSU crystal uptake assay in vivo. WT and CD1d KO mice were challenged with MSU crystal peritoneally for $6 \mathrm{~h}$. Subsequently, the macrophages (Ly6G ${ }^{-} \mathrm{F} 4 / 80^{\mathrm{hi}}$ ) were further analyzed for their SSC change, whose increasing would reflect the uptake of MSU crystal. As shown in Figures 3A,B, MSU crystal 

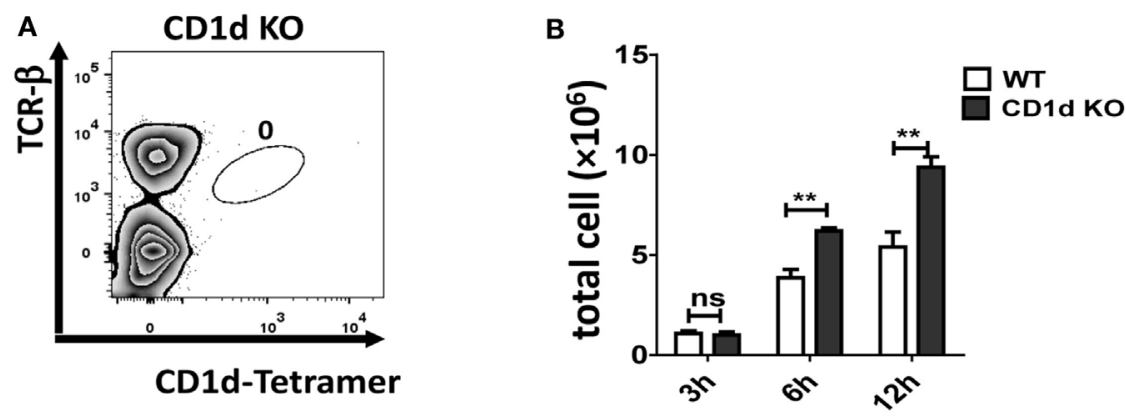

C
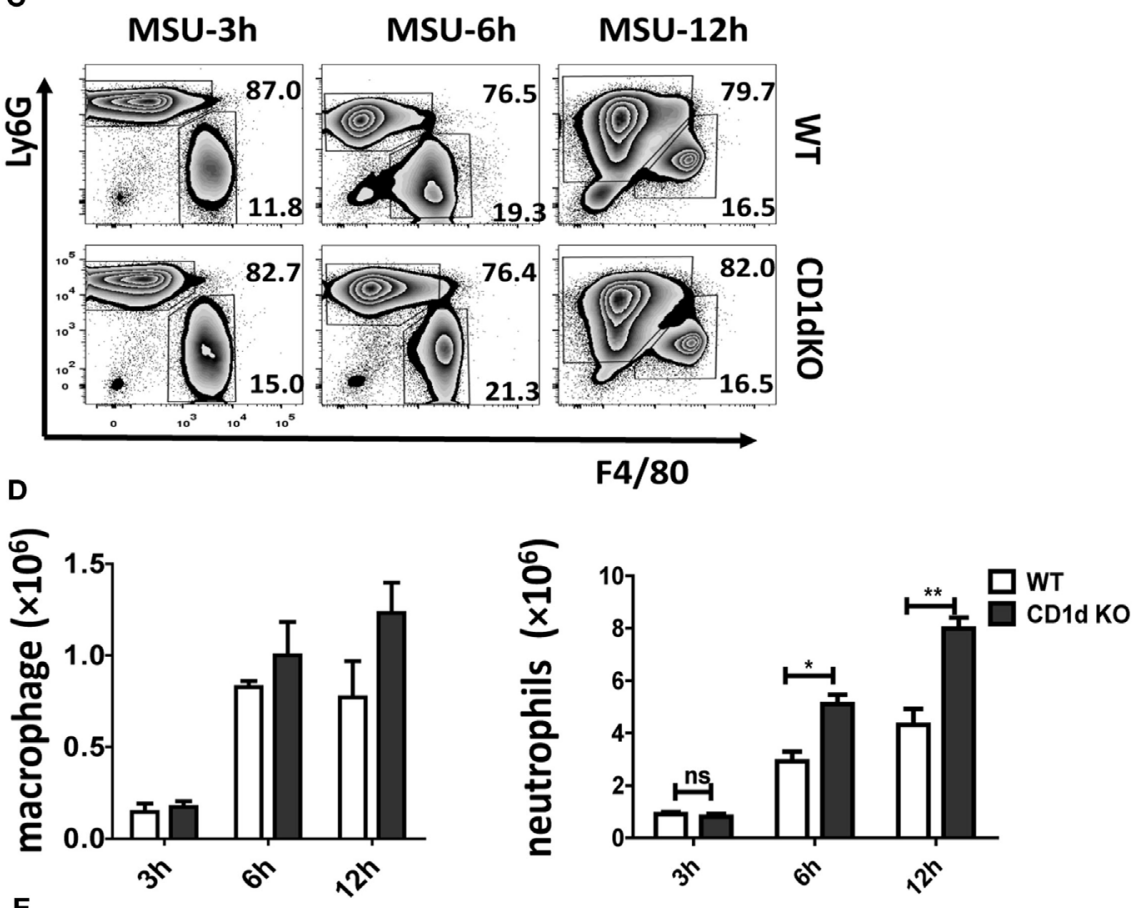

E
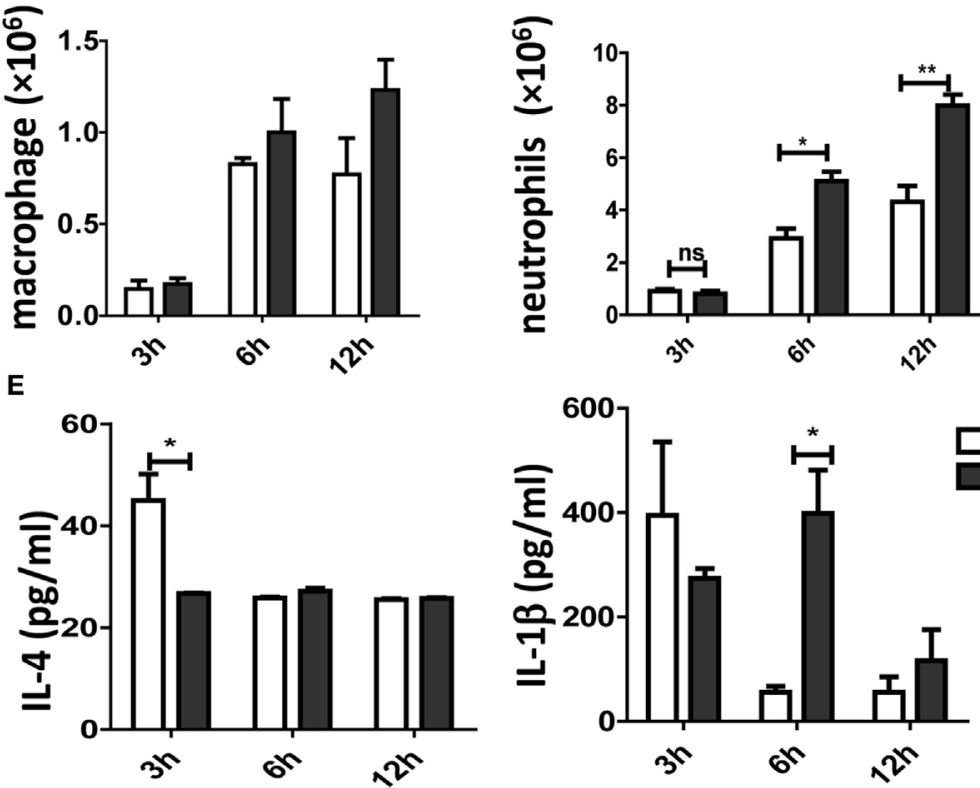

FIGURE 2 | Deletion of invariant natural killer T (iNKT) cells enhances the monosodium urate (MSU) crystal-induced inflammatory response. (A) Flow cytometry analyses of INKT cells from CD1d knockout (KO) air-pouch cavity at $12 \mathrm{~h}$ post-MSU crystal challenge; (B) a bar graph showing the total cell numbers from air-pouch cavities in wild-type (WT) and CD1d KO mice at different time points after MSU crystal treatment; (C) flow cytometry analyses of macrophages (Ly6G-F4/80 ${ }^{\text {hi) }}$ and neutrophils ( $\left(\mathrm{L} 6 \mathrm{G}^{\mathrm{hi}} \mathrm{F} 4 / 80^{-}\right.$) from air-pouch cavities based on the expression of Ly6G and F4/80 at different time points post-MSU crystal treatments. (D) The absolute numbers of infiltrating macrophages (left) and neutrophils (right) in the air-pouch cavities from WT mice (white) and CD1d KO mice (gray) over $12 \mathrm{~h}$. (E) Supernatant from air-pouch cavities was analyzed for interleukin-4 (IL-4) and interleukin-1 $\beta$ (IL-1 $\beta$ ) by enzyme-linked immunosorbent assays. Results are representative of three independent experiments. Values are the mean and SEM ( $n=3-4$ per group). Significance for all data was determined by unpaired Student's $t$-test: ns, not significant; ${ }^{*} P \leq 0.05 ;{ }^{* *} P \leq 0.01$.

phagocytosis were comparable between WT and CD1d KO mice, which indicated that MSU crystal-induced severe inflammation, including high production of IL-1 $\beta$, observed in CD1d KO mice is not due to increased MSU crystal phagocytosis. Thus, CD1d deficiency does not affect phagocytosis. Next, to rule out the possibility that lack of iNKT cells may affect macrophage death 

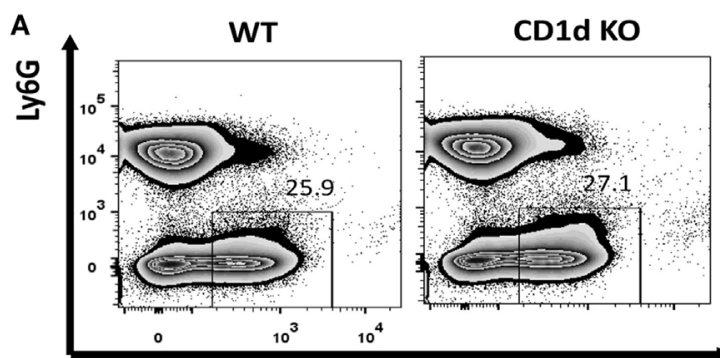

$\mathbf{F 4 / 8 0}$

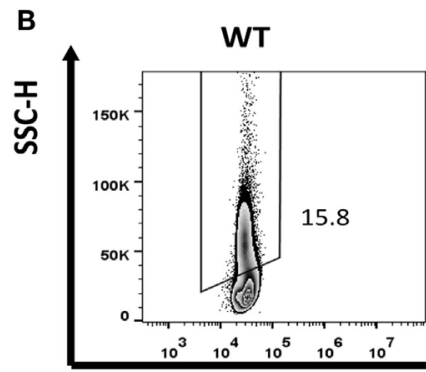

CD1d KO

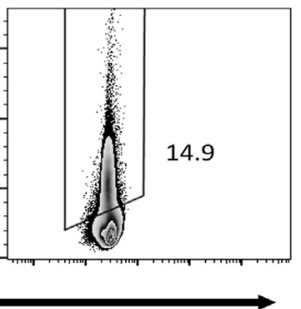

FSC-H
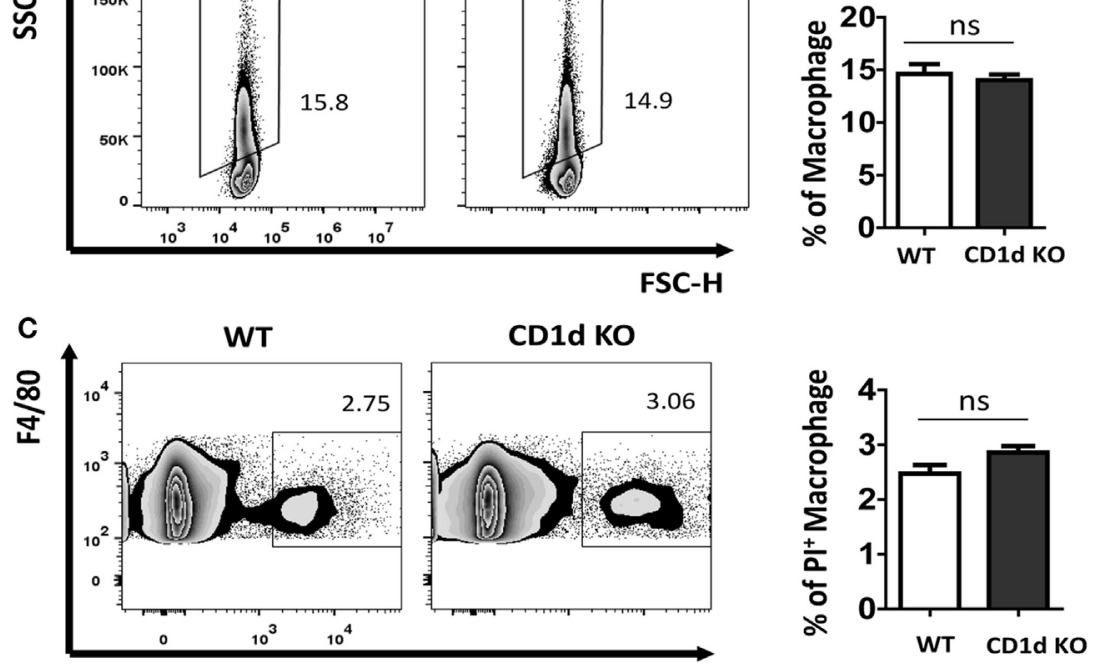

Propidium lodide

FIGURE 3 | Comparable monosodium urate (MSU) crystal phagocytosis in macrophage between wild-type (WT) and CD1d knockout (KO) mice. Flow cytometry first gated peritoneal macrophages (Ly6G-F4/80 $)$ (A) and then analyzed their side scatter (SSC) increase (B) and Pl+ dead cells (C) at $6 \mathrm{~h}$ post-MSU crystal treatment. The bar graph showed the frequencies of SSC increased macrophages (B) and $\mathrm{Pl}^{+}$macrophages (C). Results are representative of three to four mice per group. Values are the mean and SEM. ns, not significant.

during MSU crystals induced gouty inflammation, we did a cell viability assay. As shown in Figure 3C, the frequency of $\mathrm{PI}^{+}$dead macrophages was comparable between WT and CD1d KO mice. Thus, lack of $i$ NKT cells unlikely affect MSU crystal induced macrophage death.

\section{CD1d Deficiency Does Not Affect Macrophage Function}

Since CD1d is also expressed in APCs, including macrophages, to exclude the possibility that the exacerbation of MSU crystalinduced gouty inflammation in CD1d KO mice was due to the lack of CD1d in the macrophages, we examined the TNF- $\alpha$ production by $\mathrm{CD} 1 \mathrm{dKO}$ BMDMs using flow cytometry. As shown in Figure S1 in Supplementary Material, the frequencies of TNF- $\alpha$ secreting BMDMs from WT and CD1d KO mice were comparable post-MSU crystal stimulation. Thus, CD1d deficiency in macrophages may not affect their cytokine production in response to MSU crystal. Therefore, deficiency of $i$ NKT cells in CD1d KO mice likely contributes to enhanced gout development.

\section{Activation of CD4 ${ }^{+}$iNKT Cells Inhibits MSU Crystal-Induced Gouty Inflammation}

Given that $i$ NKT cells present quite early in sites of inflammation and may interact with $\mathrm{CD}^{+} \mathrm{d}^{+}$APCs, macrophages in particular, we raised the hypothesis that the cross talk between $i$ NKT cells and macrophages may interrupt MSU crystal-induced inflammation. There are at least two subsets of $i$ NKT cells, such as $\mathrm{CD}^{+}$and $\mathrm{CD}^{-}{ }^{-} i \mathrm{NKT}$ cells, which seem to possess different functions in regulating disease development (15). To investigate the contribution of $i$ NKT cells to the cellular events at the site of gouty inflammation, we performed the in vitro $i \mathrm{NKT}$ cell-BMDM coculture experiment. BMDMs from CD1d KO or WT mice were cocultured with either sorted $\mathrm{CD} 4^{+}$or $\mathrm{CD}^{-}$splenic $i \mathrm{NKT}$ cells, and treated with $\alpha$-Galcer, an agent to activate $i$ NKT cells (16). BMDMs were collected after MSU crystal stimulation, with or without the washing off of $i$ NKT cells before MSU crystal stimulation (Figure 4A). As shown in Figure 4B, BMDMs from WT mice cocultured with $\mathrm{CD}^{+} i \mathrm{NKT}$ cells produced less TNF- $\alpha$ upon MSU crystal stimulation than macrophages not cocultured with $\mathrm{CD}^{+}$ $i$ NKT cells. Coculture with $\mathrm{CD}^{-}{ }^{-} i \mathrm{NKT}$ cells did not dramatically 
change TNF- $\alpha$ production compared with the BMDMs alone. This result suggests that it was $\mathrm{CD}^{+}{ }^{+} \mathrm{NKT}$ cells rather than $\mathrm{CD}^{-}$ $i$ NKT cells that played a key role in controlling gouty inflammation. As expected, coculture of $i \mathrm{NKT}$ cells with the BMDMs from CD1d KO mice, which are unable to stimulate $i$ NKT cells due to their lack of the CD1d molecule, showed that neither $\mathrm{CD}^{-}$nor $\mathrm{CD} 4^{+} i \mathrm{NKT}$ cells inhibited TNF- $\alpha$ production (Figure 4C), which suggests that the activation of $i \mathrm{NKT}$ cells is required to inhibit TNF- $\alpha$ production in BMDMs. Thus, $\mathrm{CD}^{+} i \mathrm{NKT}$ cells regulate gouty inflammation in a CD1d-dependent manner.

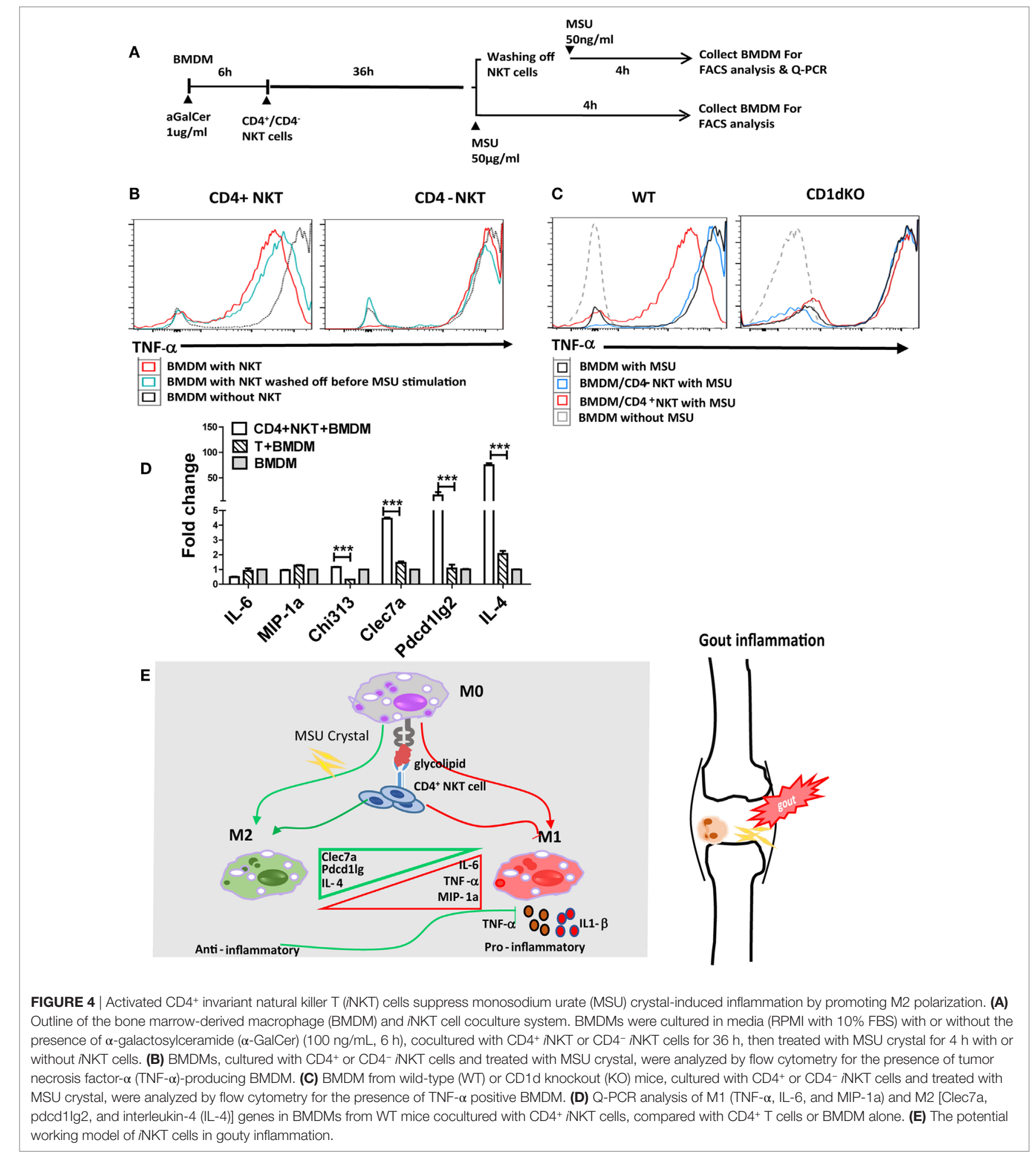




\section{Activation of CD4+iNKT Cells Enhance M2 Macrophage Polarization in MSU Crystal- Induced Gouty Inflammation}

Previous studies have suggested that activated $i$ NKT cells modulate macrophage differentiation from M1 to M2 macrophages (17-19). To test if $i$ NKT cells can regulate gouty inflammation through macrophage polarization, we assessed macrophage polarization-related cell markers using qRT-PCR analysis. As shown in Figure 4D, coculture with $\mathrm{CD} 4^{+} i \mathrm{NKT}$ cells significantly upregulated M2-related gene expressions on BMDMs, including Clec7a $(P<0.01)$, Pdcd1Ig2 $(P<0.01)$, and IL-4 $(P<0.01)$, compared with that of BMDMs cultured alone or cocultured with $\mathrm{CD}^{+}$conventional T cells; whereas expression levels of M1 markers (IL-6 and MIP-1a) were unaffected. Collectively, activation of $\mathrm{CD}^{+} i \mathrm{NKT}$ cells promotes $\mathrm{M} 2$ polarization, which may contribute to $i \mathrm{NKT}$ cell-mediated protection from MSU crystalinduced gouty arthritis.

\section{DISCUSSION}

To the best of our knowledge, this is the first study to show that $i$ NKT cells are actively involved in the development of gouty inflammation. We found that post-MSU crystal stimulation, $i \mathrm{NKT}$ cells quickly migrate to the site of inflammation, and that $i \mathrm{NKT}$ cell deficiency results in more severe MSU crystalinduced gouty inflammation in mice. Thus, early $i$ NKT cell migration to the site of inflammation is required to control gouty inflammation, which could be a key mechanism contributing to gout self-recovery. A previous study strongly suggested that $\mathrm{CD}^{+} i \mathrm{NKT}$ cells mainly produce Th2 cytokines, such as IL-4 and IL-10; and control the development of autoimmune and inflammatory diseases (20). In our study, the CD4 ${ }^{+}$, but not the $\mathrm{CD}^{-}{ }^{-}$, subset of $i \mathrm{NKT}$ cells can reduce macrophage TNF- $\alpha$ production in response to MSU crystal, which further supports previous notions. The cross talk between $i$ NKT cells and macrophages has recently been identified in different diseases (17, 21-25). $i$ NKT cells have the potential to promote macrophage polarization to the M2 subtype in adipose tissue and are involved in the development of metabolic syndrome, such as obesity, insulin resistance, and diabetes (17-19, 26). Recently, more evidence supports the notion that hyperuricemia and gout are tightly linked to metabolic syndrome (27). Consistent with previous findings in metabolic syndrome, we found that $\mathrm{CD} 4^{+}$

\section{REFERENCES}

1. Richette P, Bardin T. Gout. Lancet (2010) 375(9711):318-28. doi:10.1016/ S0140-6736(09)60883-7

2. Shi Y, Evans JE, Rock KL. Molecular identification of a danger signal that alerts the immune system to dying cells. Nature (2003) 425(6957):516-21. doi:10.1038/nature01991

3. Liu-Bryan R, Pritzker K, Firestein GS, Terkeltaub R. TLR2 signaling in chondrocytes drives calcium pyrophosphate dihydrate and monosodium urate crystal-induced nitric oxide generation. J Immunol (2005) 174(8):5016-23. doi:10.4049/jimmunol.174.8.5016

4. Liu-Bryan R, Scott P, Sydlaske A, Rose DM, Terkeltaub R. Innate immunity conferred by toll-like receptors 2 and 4 and myeloid differentiation factor 88 $i$ NKT cells can enhance M2 polarization, which may contribute to protection against MSU crystal -induced inflammation.

Accumulated clinical studies suggest that $i$ NKT cell number and subset derangements are related to the development of autoimmune and inflammatory diseases $(11,12)$. Thus, it is worthwhile to further investigate $i \mathrm{NKT}$ cell number and function in gout. Based on current findings, we suggest the potential working model for the involvement of $i \mathrm{NKT}$ cells in gouty inflammation described in Figure 4E. Overall, $i$ NKT cells quickly migrate to inflammatory site upon MSU crystal stimulation, and activation of $\mathrm{CD}^{+}{ }^{+} \mathrm{NKT}$ cells control MSU crystal-induced gouty inflammation by promoting M2 macrophage polarization. Our data strongly suggest that $\mathrm{CD} 4^{+} i \mathrm{NKT}$ cells are one of the key regulators in the control of MSU crystal-induced gouty inflammation, and that $i \mathrm{NKT}$ cells may serve as a new therapeutic target for gout.

\section{ETHICS STATEMENT}

This study was carried out in accordance with the requirements of Institutional Animal Care and Use Committee.

\section{AUTHOR CONTRIBUTIONS}

JW and QY performed most of the experiments; QZ performed some key experiments; CY maintained and genotyped mutant mice; Q-SM, LZ, JW, QY, and QZ analyzed the data; JW and Q-SM drafted the manuscript; Q-SM, YW, and JZ supervised the overall study and finalized the manuscript.

\section{ACKNOWLEDGMENTS}

The authors thank all laboratory members for their support and encouragement. This research is partially supported by the US National Institutes of Health 1R01AI119041 (Q-SM) and the Henry Ford Immunology Program grants (T71016, Q-SM; T71017, LZ).

\section{SUPPLEMENTARY MATERIAL}

The Supplementary Material for this article can be found online at http://www.frontiersin.org/articles/10.3389/fimmu.2017.01710/ full\#supplementary-material. art. 21238

5. Scott P, Ma H, Viriyakosol S, Terkeltaub R, Liu-Bryan R. Engagement of CD14 mediates the inflammatory potential of monosodium urate crystals. J Immunol (2006) 177(9):6370-8. doi:10.4049/jimmunol.177.9.6370

6. Martin WJ, Walton M, Harper J. Resident macrophages initiating and driving inflammation in a monosodium urate monohydrate crystal-induced murine peritoneal model of acute gout. Arthritis Rheum (2009) 60(1):281-9. doi:10.1002/art.24185

7. Martinon F, Petrilli V, Mayor A, Tardivel A, Tschopp J. Gout-associated uric acid crystals activate the NALP3 inflammasome. Nature (2006) 440(7081):237-41. doi:10.1038/nature04516 
8. Wang Y, Viollet B, Terkeltaub R, Liu-Bryan R. AMP-activated protein kinase suppresses urate crystal-induced inflammation and transduces colchicine effects in macrophages. Ann Rheum Dis (2016) 75(1):286-94. doi:10.1136/ annrheumdis-2014-206074

9. Das R, Sant'Angelo DB, Nichols KE. Transcriptional control of invariant NKT cell development. Immunol Rev (2010) 238(1):195-215. doi:10.1111/j.1600-065X.2010.00962.x

10. Godfrey DI, Kronenberg M. Going both ways: immune regulation via CD1ddependent NKT cells. J Clin Invest (2004) 114(10):1379-88. doi:10.1172/ JCI23594

11. Mansour S, Tocheva AS, Sanderson JP, Goulston LM, Platten H, Serhal L, et al. Structural and functional changes of the invariant NKT clonal repertoire in early rheumatoid arthritis. J Immunol (2015) 195(12):5582-91. doi:10.4049/ jimmunol.1501092

12. Jin HM, Kee SJ, Cho YN, Kang JH, Kim MJ, Jung HJ, et al. Dysregulated osteoclastogenesis is related to natural killer T cell dysfunction in rheumatoid arthritis. Arthritis Rheumatol (2015) 67(10):2639-50. doi:10.1002/art.39244

13. Landis RC, Yagnik DR, Florey O, Philippidis P, Emons V, Mason JC, et al. Safe disposal of inflammatory monosodium urate monohydrate crystals by differentiated macrophages. Arthritis Rheum (2002) 46(11):3026-33. doi:10.1002/ art.10614

14. Schorn C, Janko C, Latzko M, Chaurio R, Schett G, Herrmann M. Monosodium urate crystals induce extracellular DNA traps in neutrophils, eosinophils, and basophils but not in mononuclear cells. Front Immunol (2012) 3:277. doi:10.3389/fimmu.2012.00277

15. Crowe NY, Coquet JM, Berzins SP, Kyparissoudis K, Keating R, Pellicci DG, et al. Differential antitumor immunity mediated by NKT cell subsets in vivo. J Exp Med (2005) 202(9):1279-88. doi:10.1084/jem.20050953

16. Wingender G, Birkholz AM, Sag D, Farber E, Chitale S, Howell AR, et al. Selective conditions are required for the induction of invariant NKT cell hyporesponsiveness by antigenic stimulation. J Immunol (2015) 195(8):3838-48. doi:10.4049/jimmunol.1500203

17. Ji Y, Sun S, Xu A, Bhargava P, Yang L, Lam KS, et al. Activation of natural killer T cells promotes M2 Macrophage polarization in adipose tissue and improves systemic glucose tolerance via interleukin-4 (IL-4)/STAT6 protein signaling axis in obesity. J Biol Chem (2012) 287(17):13561-71. doi:10.1074/ jbc.M112.350066

18. Kawanishi N, Yano H, Yokogawa Y, Suzuki K. Exercise training inhibits inflammation in adipose tissue via both suppression of macrophage infiltration and acceleration of phenotypic switching from M1 to M2 macrophages in high-fat-diet-induced obese mice. Exerc Immunol Rev (2010) 16: 105-18.
19. Zhang H, Xue R, Zhu S, Fu S, Chen Z, Zhou R, et al. M2-specific reduction of CD1d switches NKT cell-mediated immune responses and triggers metaflammation in adipose tissue. Cell Mol Immunol (2017). doi:10.1038/cmi. 2017.11

20. Balato A, Unutmaz D, Gaspari AA. Natural killer T cells: an unconventional T-cell subset with diverse effector and regulatory functions. J Invest Dermato (2009) 129(7):1628-42. doi:10.1038/jid.2009.30

21. Tocheva AS, Mansour S, Holt TG, Jones S, Chancellor A, Sanderson JP, et al. The clonal invariant NKT cell repertoire in people with type 1 diabetes is characterized by a loss of clones expressing high-affinity TCRs. J Immunol (2017) 198(4):1452-9. doi:10.4049/jimmunol.1600255

22. Song L, Asgharzadeh S, Salo J, Engell K, Wu HW, Sposto R, et al. Valpha24invariant NKT cells mediate antitumor activity via killing of tumor-associated macrophages. J Clin Invest (2009) 119(6):1524-36. doi:10.1172/JCI37869

23. Lynch L, Hogan AE, Duquette D, Lester C, Banks A, LeClair K, et al. iNKT cells induce FGF21 for thermogenesis and are required for maximal weight loss in GLP1 therapy. Cell Metab (2016) 24(3):510-9. doi:10.1016/j.cmet. 2016.08.003

24. Lukens JR, Kanneganti TD. Fat chance: not much against NKT cells. Immunity (2012) 37(3):447-9. doi:10.1016/j.immuni.2012.09.006

25. Coppieters K, Dewint P, Van Beneden K, Jacques P, Seeuws S, Verbruggen G, et al. NKT cells: manipulable managers of joint inflammation. Rheumatology (Oxford) (2007) 46(4):565-71. doi:10.1093/rheumatology/kel437

26. Lynch L, Michelet X, Zhang S, Brennan PJ, Moseman A, Lester C, et al. Regulatory iNKT cells lack expression of the transcription factor PLZF and control the homeostasis of T(reg) cells and macrophages in adipose tissue. Nat Immunol (2015) 16(1):85-95. doi:10.1038/ni.3047

27. Puig JG, Martinez MA. Hyperuricemia, gout and the metabolic syndrome. Curr Opin Rheumatol (2008) 20(2):187-91. doi:10.1097/ BOR.0b013e3282f4bled

Conflict of Interest Statement: The authors declare that the research was conducted in the absence of any commercial or financial relationships that could be construed as a potential conflict of interest.

Copyright (c) 2017 Wang, Yang, Zhang, Yin, Zhou, Zhou, Wang and Mi. This is an open-access article distributed under the terms of the Creative Commons Attribution License (CC BY). The use, distribution or reproduction in other forums is permitted, provided the original author(s) or licensor are credited and that the original publication in this journal is cited, in accordance with accepted academic practice. No use, distribution or reproduction is permitted which does not comply with these terms. 